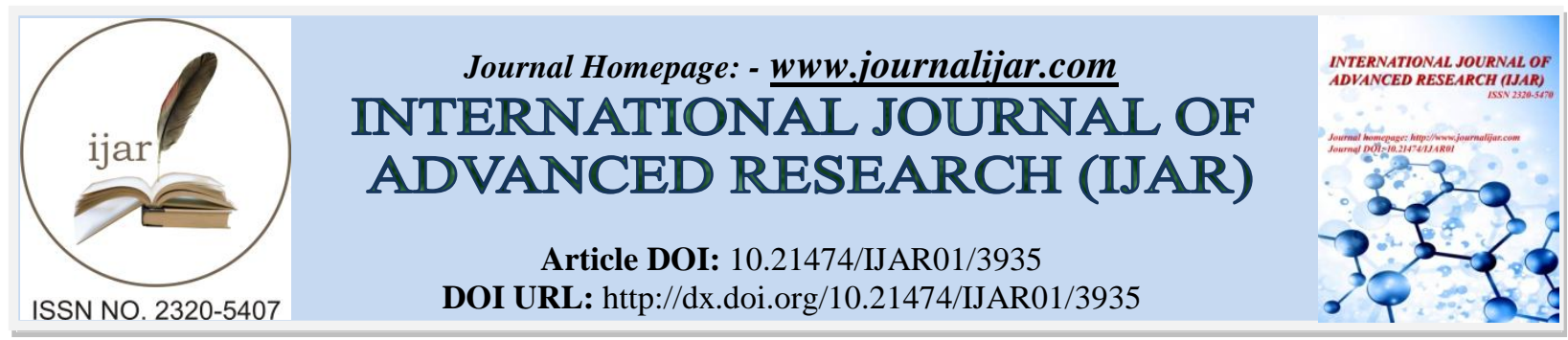

RESEARCH ARTICLE

\title{
FLEXURAL STRENGTH OF TWO-WAY RC SLABS RETROFITTED USING BASALT FIBER REINFORCED POLYMER (BFRP) WITH MECHANICAL ANCHORAGE.
}

Shubhalakshmi.B.S $\mathbf{1}$, H N Jagannatha Reddy ${ }^{2}$ and K Arjun ${ }^{1}$.

1. Assistant Professor's, Department of Civil Engineering, Dayananda Sagar College of Engineering, Bengaluru, India-560078.

2. Professor, Department of Civil Engineering, Bangalore Institute of Technology, Bengaluru, India-560004

\section{Manuscript Info}

Manuscript History

Received: 17 February 2017

Final Accepted: 12 March 2017

Published: April 2017

Key words:-

BFRP, Fiber, Flexure, Retrofitted,

Strengthening, Wrapping.

\section{Abstract}

Strengthening of existing reinforced concrete structural elements has been one of the most important activities in civil engineering. The upgrading of existing structures is an integral part of structural engineering practice. A slab is a flat two dimensional planar structural element having small thickness, compared to its other two dimensions. Reinforced concrete slabs are one of the most commonly used structural elements. Composites are used because overall properties of the composites are superior to those of the individual components. Basalt fibers are made from basalt rocks which are the most common rock type in the earth's crust. An anchor bolt is used to attach objects or structures to concrete. There are many types of anchor bolts, consisting of designs that are mostly proprietary to the manufacturing companies. All consist of a threaded end, to which a nut and washer can be attached for the external load. The experimental work was conducted on slabs to study the effect of BFRP on flexural behavior of the slabs under the static loads, using cross wrapping technique with mechanical anchoring. The BFRP was to be introduced to slabs in the form of cross wrapping at flexural zone by wet lay-up technique then it was anchored with bolts and plates as per the guidelines of the manufacturers. Control slabs were casted and tested after 28 days under uniformly distributed loading case. Strengthened slabs were tested after 6 days of strengthening and once after it were anchored. From the experimental results it was revealed that the initial crack strength and ultimate load strength of retrofitted slabs with mechanical anchoring are found to be increasing by at least $39.585 \%$ comparatively and stiffness of wrapped slabs were found to be increased.

Copy Right, IJAR, 2017,. All rights reserved.

\section{Introduction:-}

Strengthening of existing reinforced concrete structural elements has been one of the most important activities in civil engineering. The upgrading of existing structures is an integral part of structural engineering practice. Strengthening or retrofitting of older structures to resist higher design loads or increase ductility has been accomplished with traditional materials such as externally bonded steel plates and steel jackets since in the 1960s. In recent years an increased application of new repair and strengthening techniques of reinforced concrete structures

Corresponding Author:- Shubhalakshmi B S. 
has been noted. Structural repair and rehabilitation of reinforced concrete structures has become an increasing important option for all deteriorated/damaged structures to restore, enhance the load carrying capacity and increase the life span of the structure. A slab is a flat two dimensional planar structural element having thickness, small compared to its other two dimensions. Reinforced concrete slabs are among the most commonly used structural elements. The use of FRP to strengthen civil engineering structures started in 1980's. FRP system that is nonmetallic material is considered to be a beneficial technique. Composites are used because overall properties of the composites are superior to those of the individual components. These new materials are applicable to both construction of new structures and maintenance and rehabilitation of existing structures. Fiber-reinforced composites are used in some of the most advanced constructions, and therefore most expensive. Basalt fibers are made from basalt rocks which are the most common rock type in the earth's crust. The fibers are manufactured from melted rock which is then extruded through small nozzles to produce continuous basalt fiber.

\section{Materials:-}

Basalt fibers are made from basalt rocks which are the most common rock type in the earth's crust. The fibers are manufactured from melted rock which is then extruded through small nozzles to produce continuous basalt fiber. Basalt FRP (BFRP) is the latest FRP composite that has developed within the last ten years and has been proven to have advantages in achieving the goal of enhancing safety and reliability of structural systems compared with the conventional carbon, glass and aramid FRP composites. BFRP shows advantageous characteristics in mechanical, chemical and high ratio of performance to cost in comparison to CFRP, GFRP, AFRP, steel bars. BFRP has a higher strength and modulus, a similar cost, and more chemical stability compared with E-glass FRP; a wider range of working temperatures and much lower cost than carbon FRP (CFRP); over five times of strength and around one third of density than commonly used low-carbon steel bars. Due to above advantages, BFRP has already become an attractive alternative for replacing conventional construction materials and is expected to enhance structural safety and sustainability.

Table 1:- Properties of Udl Basalt Fabric (Bas Uni 230).

\begin{tabular}{|c|c|}
\hline Properties & UD Basalt Fabric \\
\hline Fibber orientation & (BAS UNI 230) \\
\hline Uni-directional \\
\hline Weight of fibre $\left(\mathrm{g} / \mathrm{m}^{2}\right)$ & 230 \\
\hline Fibber thickness $(\mathrm{mm})$ & 0.100 \\
\hline Ultimate elongation (percentage) & 2.6 \\
\hline Primary fibre tensile strength (Mpa) & 2100 \\
\hline Tensile modulus (Gpa) & 105 \\
\hline
\end{tabular}

An anchor bolt is used to attach objects or structures to concrete. There are many types of anchor bolts, consisting of designs that are mostly proprietary to the manufacturing companies. All consist of a threaded end, to which a nut and washer can be attached for the external load. Mechanical anchors are the type of anchors bolts which works in the mechanical means to hold the base material such as brickwork, blockwork, stone, standard and reinforced concrete. Generally mechanical type anchor bolts are simple, effective and reliable use in hard base materials, common type of mechanical anchors bolts are expansion or wedge type anchors and screw anchors. Mechanical type anchors are commonly used because their ease of installation and economical, compared to chemical anchors. Wedge or expansion anchors are used in this research work. An anchor plate is a MS plate which is used as a fixture with a specified diameter of hole, through which certain diameter of anchor bolt runs into the base material such as brickwork, blockwork, stones and reinforced hardened concrete. The main purpose of the plate used is to hold the FRP sheets against the load and prevent de-bonding. 


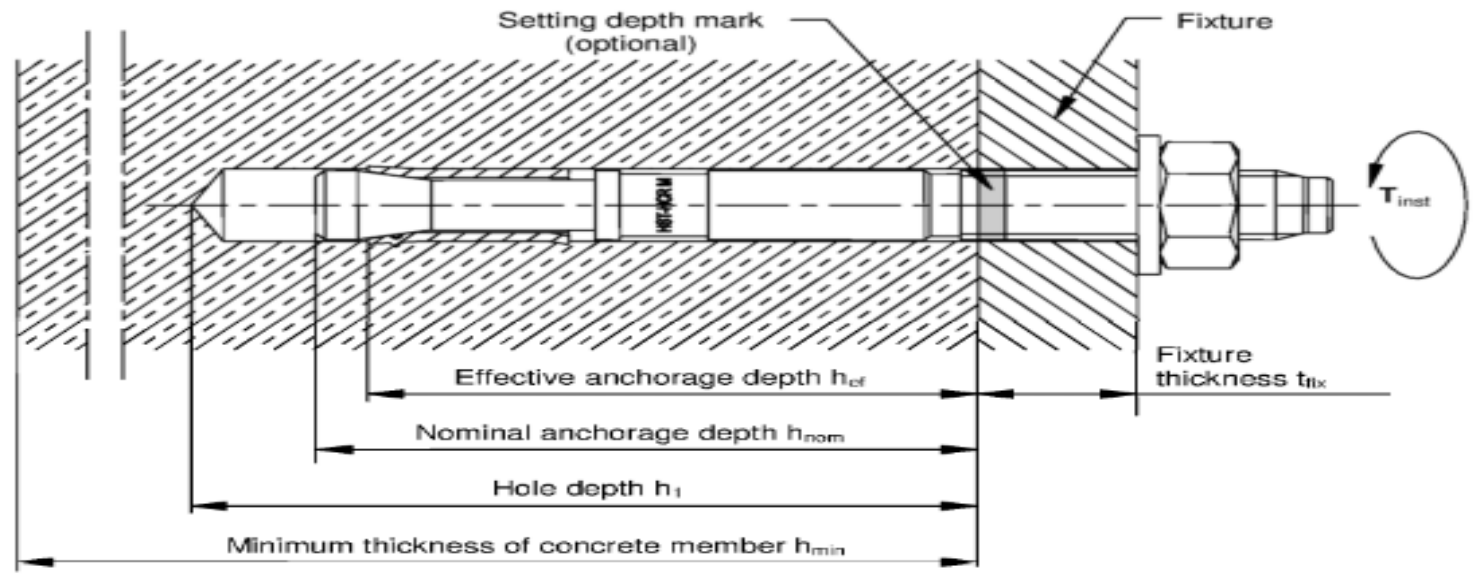

Fig. 1:- Labelling of a typical bolt.

\begin{tabular}{|c|c|c|c|c|c|c|c|c|}
\hline Anchor type / size & & & M8 & M10 & M12 & M16 & $\begin{array}{c}\text { M20 } \\
\text { HST, HST.R } \\
\text { only }\end{array}$ & $\underset{\substack{\text { HST, HST-R } \\
\text { only }}}{\text { M24 }}$ \\
\hline \multicolumn{9}{|c|}{ all types (HST, HST-R, HST-HCR) } \\
\hline Nominal diameter of drill bit & $\mathrm{d}_{0}$ & [mm] & 8 & 10 & 12 & 16 & 20 & 24 \\
\hline Cutting diameter of drill bit & $\mathrm{d}_{\text {cut }} \leq$ & [mm] & 8,45 & 10,45 & 12,50 & 16,50 & 20,55 & 24,55 \\
\hline Depth of drill hole & $h_{1} \geq$ & {$[\mathrm{mm}]$} & 65 & 80 & 95 & 115 & 140 & 170 \\
\hline Clearance hole in the fixture & $d_{f} \leq$ & {$[\mathrm{mm}]$} & 9 & 12 & 14 & 18 & 22 & 26 \\
\hline Effective anchorage depth & $h_{e t}$ & {$[\mathrm{~mm}]$} & 47 & 60 & 70 & 82 & 101 & 125 \\
\hline Nominal anchorage depth & $h_{\text {non }}$ & [mm] & 55 & 69 & 80 & 95 & 117 & 143 \\
\hline Torque moment & $\mathrm{T}_{\text {iret }}$ & {$[\mathrm{Nm}]$} & 20 & 45 & 60 & 110 & 240 & 300 \\
\hline Maximum thickness of fixture & $t_{\text {iix,max }}$ & [mm] & 195 & 200 & 200 & 235 & 305 & 330 \\
\hline
\end{tabular}

Fig. 2:- Anchor dimensions and installation data.

\section{Method:-}

The experimental study was conducted to test the reinforced concrete slabs. This includes testing a control slab and retrofitted slabs. The main objective of the investigation was to study the flexural and ductility behavior of concrete slabs retrofitted with BFRP sheets with mechanical anchorage bonded onto the flexural zone of the slab. Bolts used in this research work are HILTI's wedge anchors or expansion anchors of $8 \mathrm{~mm}$ diameter 3inch length HST wedge anchor bolts. And 3mm thickness of $65 \times 200 \mathrm{~mm}$ dimension MS plate as a fixture or anchor plates used in this work. Totally 24 anchors bolts and 4 MS plates were used per anchored slabs.

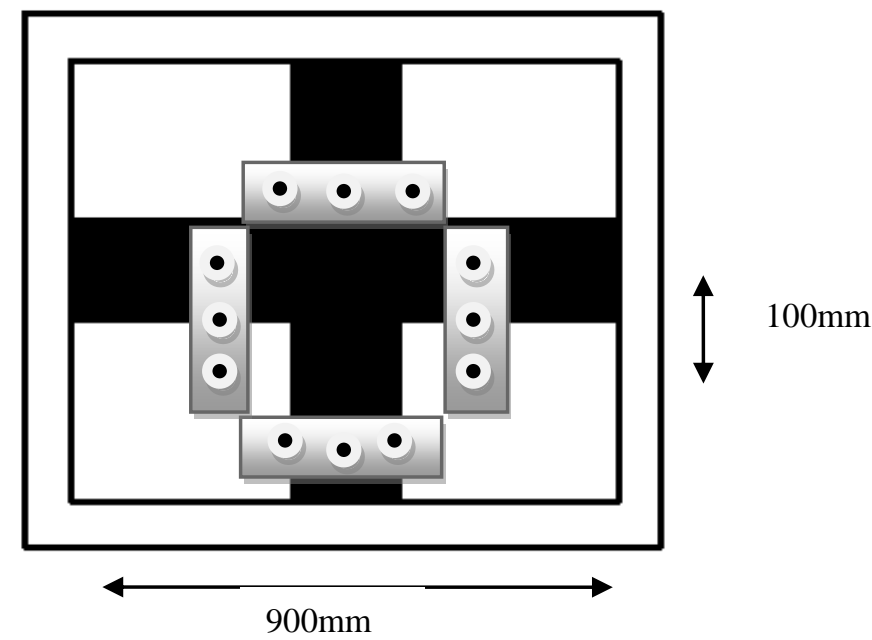

Fig.3:- Externally bonded BFRP sheets with anchorage system. 
The FRP application included the resin system made of two parts namely the resin, the hardener and the fiber sheets. The concrete surface was cleaned and completely dried before the resin is applied. A first coat of thin layer of resin was applied and the FRP fabric precut to the desired dimension was then wrapped directly onto the surface. After the application of the FRP sheet wrap, a second layer of resin was applied to the surface to allow impregnation. The second layer of FRP sheet was then impregnated on top of the first layer. Adequate pressure was applied until the resin was squeezed out. The wrapped specimens were left at room temperature to allow air curing for seven days to allow bonding of the laminates. Installation of wedge or expansion anchor bolts performed in four steps as fallows;

1. Drill a hole with the prescribed diameter mond core bit. Diameter of drill bit used should equal to diameter of anchor bolt.

2. Cleaning of hole.

3. Using a hammer, tap the pre-assembled anchor through the object being anchored and into the hole. The anchor should be seated firmly against the base plate.

4. Tighten bolt or nut to the specified torque, using a torque wrench or with handy mechanical tools.
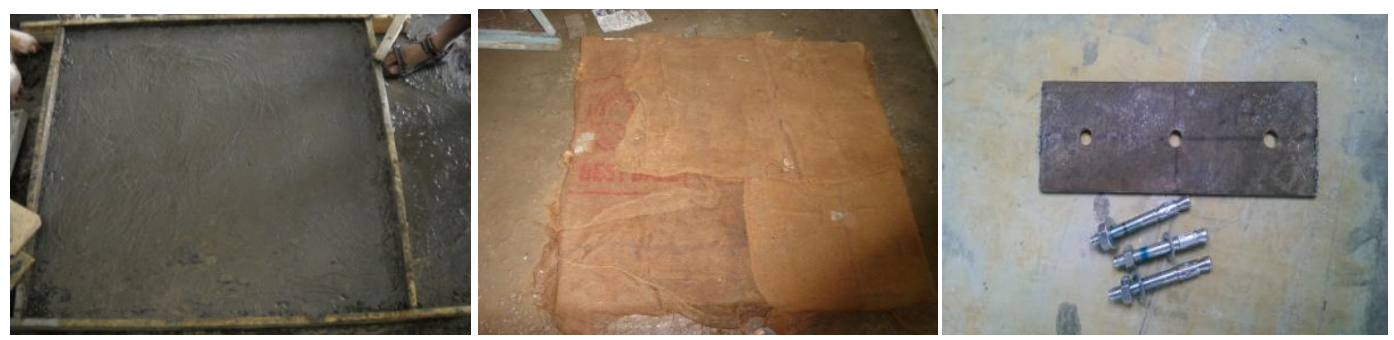

Fig.4:- Compacted concrete, curing of slab using gunny bags, and anchor bolts and plate.
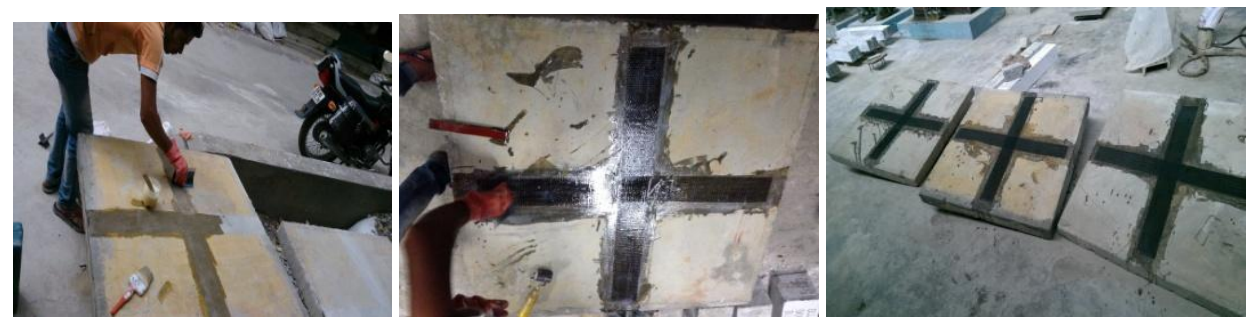

Fig.5:- Application of BFRP Sheets
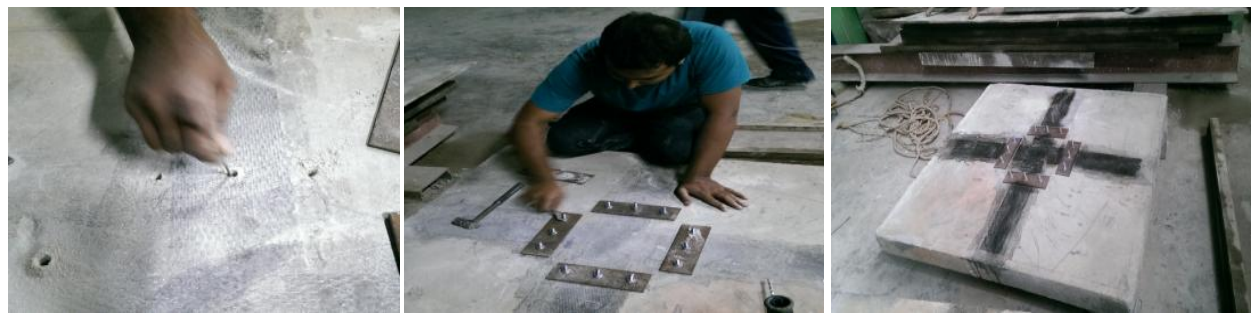

Fig.6:- Installation of anchors carried out as per previously specified steps in this project work.

Test specimens were subjected to flexural test. The same testing program was applied to both controlled as well as on retrofitted slabs with mechanical anchoring. The specimen was also painted with lime wash in order to easily note the crack pattern of the specimen. The setup was carried out with a 25 ton loading frame, a loading jack was fixed on top of the specimen to apply load. To give the udl effect to the slab, loading channels were used such that the loads that were centrally applied were uniformly distributed on the slab as shown in figure 7. The deflection at the bottom of the slab was measured using dial gauge. Totally five dial gauge's were used for this experiment. The placement of these dial gauges are as one at the centre of the slab and other four at different points as shown in the figure 7 .

The load was applied using a hand held lever with uniform increment up to the failure load. The dial gauge readings were noted down to calculate the deflection of the slab. The load was incremented manually and the readings of the 
dial gauge were taken at an interval of $2 \mathrm{kN}$. The results and the graphs are discussed separately. The deflection was tabulated at each increment of loading. Also the complete crack patterns and the failure load were recorded in each test.
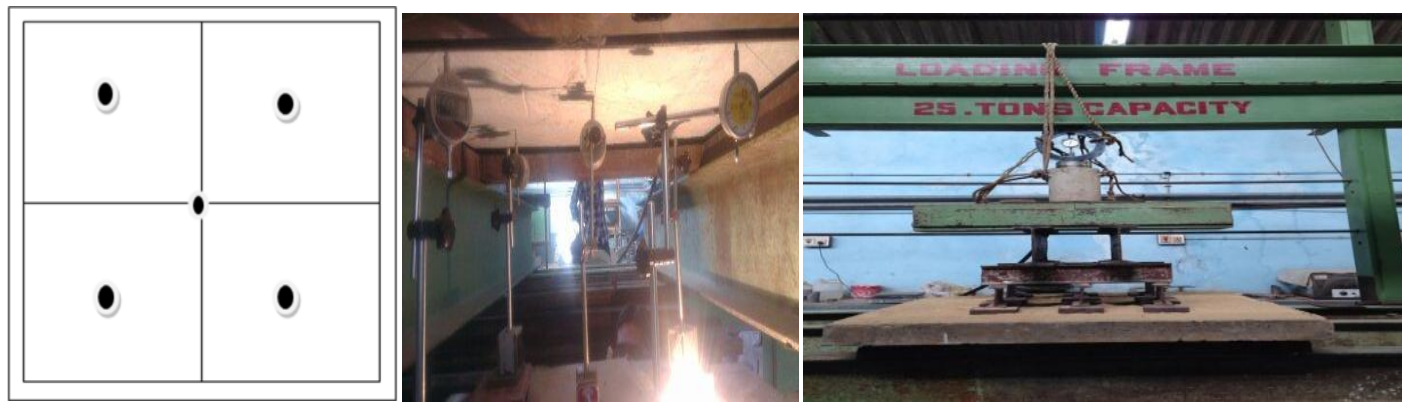

Fig.7:- Layout and positioning of dial gauges, Test setup.

\section{Result and Discussion:}

For the control and retrofitted with mechanical anchoring slab, the deflection was measured at the mid span and other four points. The load-deflection curve has been plotted for the same as shown below.
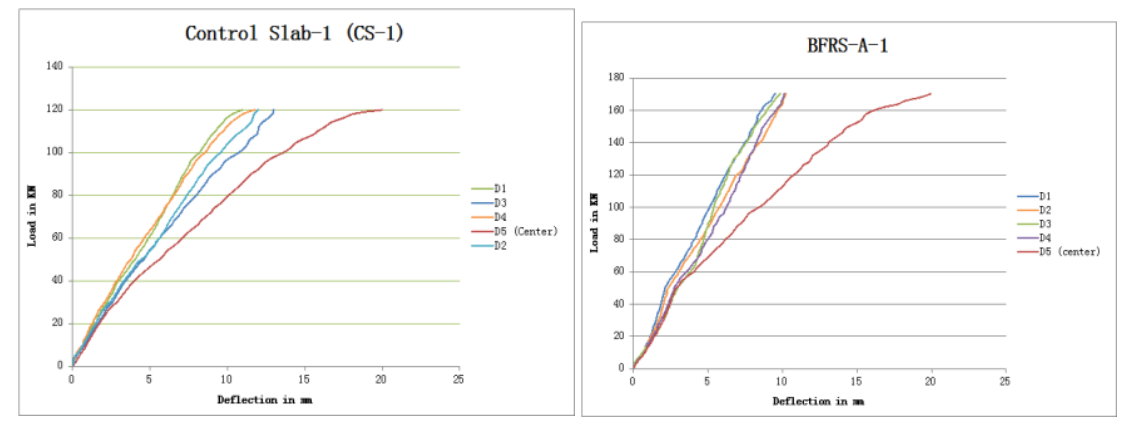

Fig. 8:- Load v/s Deflection Curves for Control Slab and retrofitted slab
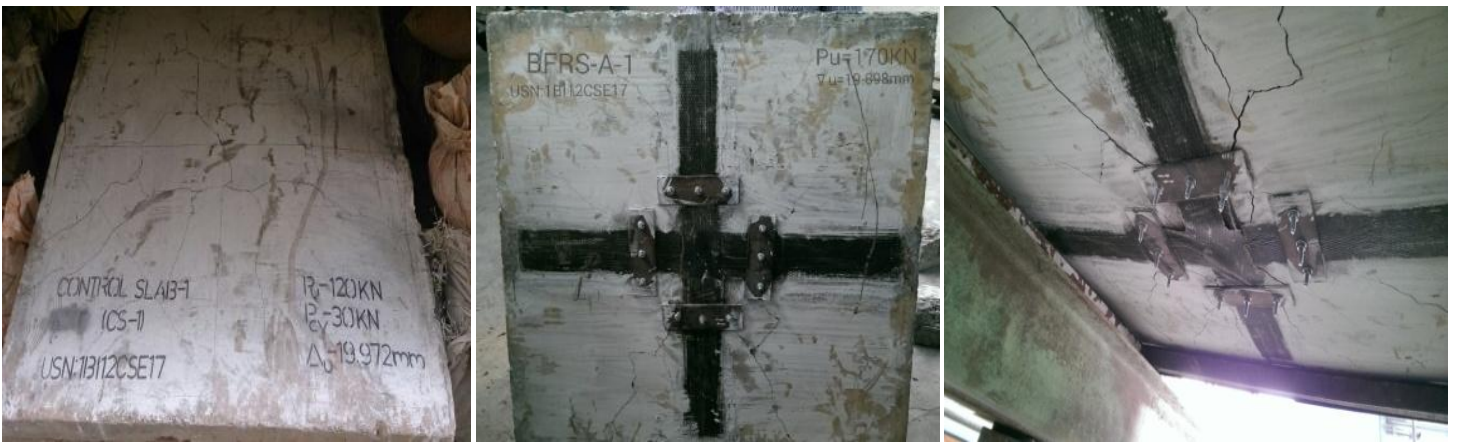

Fig 9:- Crack pattern of control slab and retrofitted slab, Mode of failure: Fracture of FRP and Failure of anchor Bolt

Table 2:- Comparison of Experimental Results.

\begin{tabular}{|c|c|c|c|}
\hline Type of slab & Type of wrapping & $\begin{array}{c}\text { Failure load } \\
(\mathbf{k N})\end{array}$ & \% Variation \\
\hline Control slab & - & 120 & - \\
\hline $\begin{array}{c}\text { Basalt fibre retrofitted with mechanical } \\
\text { anchoring slab 1 }\end{array}$ & Cross type wrapping & 170 & $41.67 \%$ \\
\hline $\begin{array}{c}\text { Basalt fibre retrofitted with mechanical } \\
\text { anchoring slab 2 }\end{array}$ & Cross type wrapping & 165 & $37.5 \%$ \\
\hline
\end{tabular}




\section{Conclusions:-}

This experimental study investigate the cross type BFRP wrapping effect on ultimate load carrying capacity, deflection and stiffness of slabs compared with control slab.

- All the two-way RC slabs strengthened with BFRP with mechanical anchoring in single layer were capable to take more load than the slab without strengthening (control slab).

- Suitable anchorage system was introduced to prevent the de-bonding of BFRP wrap in the flexural zone to utilize the complete strength of the BFRP sheets.

- The $8 \mathrm{~mm}$ wedge or expansion anchor bolts with MS plate of $3 \mathrm{~mm}$ thick compositely acts as an anchorage system was provided at the de-bonded region in the flexural zone.

- The slabs retrofitted with BFRP cross wrap with mechanical anchoring were found to effective in the increase of load carrying capacity by $39.5 \%$ as compared to control slab.

- The slabs retrofitted with BFRP sheets with anchorage were failed by fracture of BFRP wrapped in the flexural zone with complete utilization of its strength and anchor bolts loosened due to increase of crack width.

- The stiffness was found to be high for slabs retrofitted with BFRP sheets as compared to control slabs.

Overall it shown that BFRP sheets effectively increases the load carrying capacity and stiffness of slabs.

\section{References:-}

1. G. Maariappan \& R. Singaravadivelan (2013): "Studies on Behavior of RCC Beam-Column Joint Retrofitted with Basalt Fiber Reinforced Polymer Sheet" Global Journal of Researches in Engineering Civil And Structural Engineering, Vol 13, Issue 5, Version 1.0, ISSN: 0975-5861

2. Gao Ma, Hui Li, and Jian Wang (2013): "Experimental Study of the Seismic Behavior of an EarthquakeDamaged Reinforced Concrete Frame Structure Retrofitted with Basalt Fiber-Reinforced Polymer" Journal of Composites for Construction, (c) ASCE, ISSN 1090-0268/04013002 DOI: 10.1061/ (ASCE) CC.19435614.0000413. American Society of Civil Engineers.

3. Fang Yuan, Jinlong Pan, and C. K. Y. Leung(2013): "Flexural Behaviors of ECC and Concrete/ECC Composite Beams Reinforced with Basalt Fiber-Reinforced Polymer" Journal of Composites for Construction, Vol. 17, No. 5,ASCE, ISSN 1090-0268

4. Mr. Gore Ketan R, Prof. Suhasini M.Kulkarni (2013): “The Performance of Basalt Fiber in High Strength Concrete", ISSN: 0975-6744, Vol 2.

5. R.Anandakumar, Dr.C.Selvamony, Dr.S.U.Kannan(2013): "Retrofitting Of Concrete Specimens And Reinforced Concrete piles Using Basalt Fibers" International Journal of Engineering Science Invention ISSN Vol. 2 Issue 8

6. OUYANG Li-jun, LU Zhou-dao and CHEN Wei-zhen(2012): "Flexural Experimental Study On Continuous Reinforced Concrete Beams Strengthened With Basalt Fiber Reinforced Polymer/Plastic" Shanghai Jiaotong University and Springer-Verlag Berlin Heidelberg.

7. R Singaravadivelan, N Sakthieswaren and Dr.K.L.Muthuramu (2012): "Experimental Investigation on the Behavior of Flexural Strengthening of Beam Using Basalt fiber" International Conference on Automotive, Mechanical and Materials Engineering, ICAMME.

8. Wu Zhishen, Wang Xin, Wu Gang(2012): “Advancement Of Structural Safety And Sustainability With Basalt Fiber Reinforced Polymers" Conference on FRP composites in Civil Engineering, CICE

9. Marco Di Ludovico; Andrea Prota; and Gaetano Manfredi(2010): "Structural Upgrade Using Basalt Fibers for Concrete Confinement" Journal of Composites for Construction, Vol. 14, No. 5.ASCE, ISSN 10900268/2010/5-541-552

10. L. Michel, E. Ferrier, A. Agbossou, P. Hameli n(2009): "Flexural stiffness modelling of RC slab strengthened by externally bonded FRP" Composites: Part B 40, 758-765

11. Shenghu CAO \& Zhishen (2008): "Tensile Properties of FRP Composites at Elevated and High Temperatures" Journal of Applied Mechanics Vol 11, pp.963-970.

12. G. Wu, D.S. GU, Z.S. Wu, J.B. Jiang and X.Q. Hu (2007): "Comparative Study on Seismic Performance of Circular Concrete Columns Strengthened With BFRP and CFRP Composites" Asia-Pacific Conference on FRP in Structures.

13. Van de Velde K., Kiekens P., Van Langenhove L. "Basalt Fibres as Reinforcement for Composites" Department of Textiles, Ghent University, Technologiepark 907, B-9052 Zwijnaarde, Belgium

14. WU Gang, WU Zhi-shen, Lü Zhi-tao, WEI hong-chang, HU Xian-qi, "The Outstanding Advantages of Applying Basalt Fiber Polymer (BFRP) in Structure Post-earthquake Strengthening and Rehabilitation" International Institute for Urban Systems Engineering, SEU, Nanjing 210096, China; Department of Urban \& 
Civil Engineering, Ibaraki University, Hitachi 316-8511, Japan; Beijing Texida Technology Group, Beijing 100011, China; Zhejiang GBF Basalt Fiber Co., Ltd. Hengdian, 322118)

15. Wu Zhishen, Wu Gang, Wang Xin, Hu Xianqi, Jiang Jianbiao, "New Progress in R \& D of Basalt Fibres and BFRP in Infrastructure Engineering" International Institute for Urban Systems Engineering Nanjing 210096, Department of Urban \& Civil Engineering Ibaraki University Hitachi 3168511 Japan, Zhejiang GBF Co., Ltd Hengdian 322118, Beijing Texida Technology R \& D Co., Ltd Beijing 100011 